\title{
Effects of high sodium intake and diuretics on the circadian rhythm of blood pressure in type 2 diabetic patients treated with an angiotensin II receptor blocker
}

Takashi Uzu · Masayoshi Sakaguchi · Yukiyo Yokomaku · Shinji Kume $\cdot$ Masami Kanasaki Keiji Isshiki · Shin-ichi Araki · Toshiro Sugiomoto · Daisuke Koya · Masakazu Haneda • Atsunori Kashiwagi

Published online: 14 April 2009

(C) Japanese Society of Nephrology 2009

\section{Erratum to: Clin Exp Nephrol}

DOI 10.1007/s10157-009-0157-7

The legend for Fig. 3 appeared incorrectly in the article cited above. The correct legend is as follows.
The online version of the original article can be found under doi:10.1007/s10157-009-0157-7.

T. Uzu ( $₫) \cdot$ M. Sakaguchi $\cdot$ Y. Yokomaku $\cdot$ S. Kume ·

M. Kanasaki · K. Isshiki · S. Araki · T. Sugiomoto ·

A. Kashiwagi

Department of Medicine, Shiga University of Medical Science,

Otsu, Shiga, Japan

e-mail: takuzu@belle.shiga-med.ac.jp

D. Koya

Division of Endocrinology and Metabolism,

Department of Medicine, Kanazawa Medical University,

Kanazawa, Japan

M. Haneda

Department of Medicine, Asahikawa Medical College,

Asahikawa, Japan
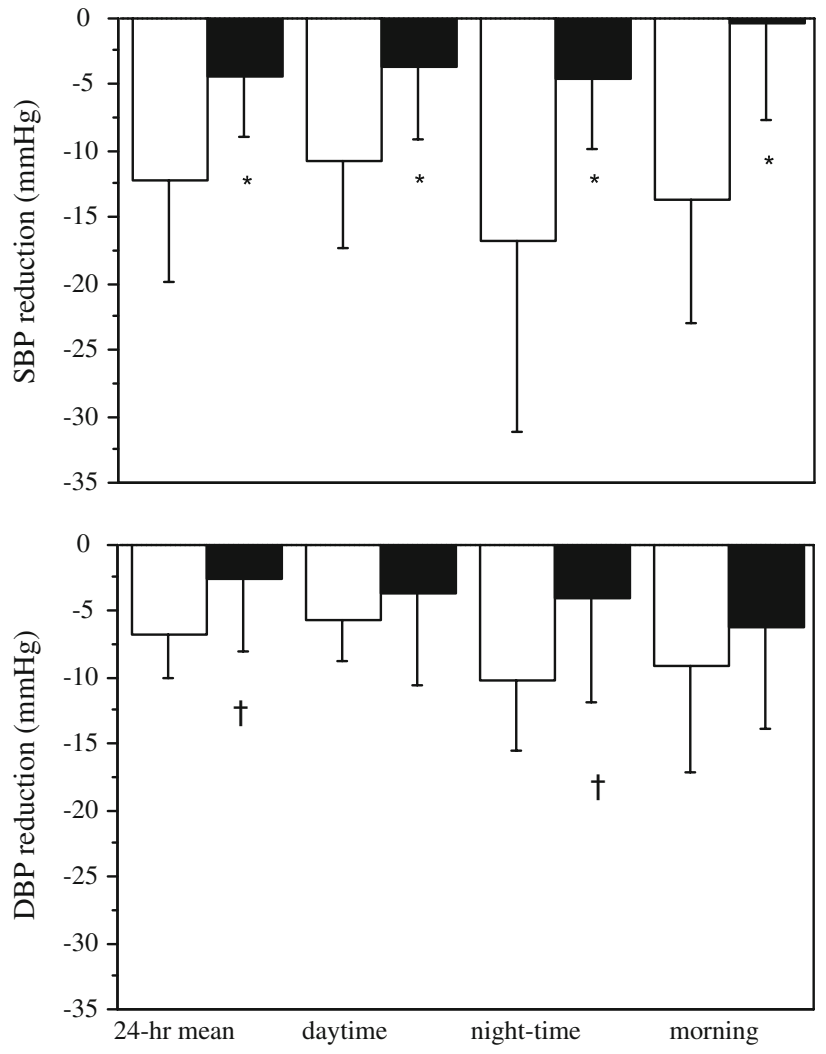

Fig. 3 Mean change in BP values from baseline in 24-h mean, daytime, night-time and morning SBP and DBP obtained after 24 weeks of treatment with losartan $(50 \mathrm{mg})$ plus hydrochlorothiazide $(12.5 \mathrm{mg}$ ) (white bars) and valsartan monotherapy $(160 \mathrm{mg}$ ) (black bars). Mean $\pm \mathrm{SD}, \uparrow P<0.05$ and $* P<0.01$ between treatments. $S B P$ systolic blood pressure, $D B P$ diastolic blood pressure 